\title{
Comparison of estimated daily dietary fluoride intake by food diary and duplicate-plate collection methods
}

\author{
F. V. Zohoori ${ }^{1}$, N. Omid ${ }^{1}$, A. M. Batterham ${ }^{1}$, W. T. O'Hare ${ }^{1}$ and A. Maguire ${ }^{2}$ \\ ${ }^{1}$ Health and Social Care Institute, Teesside University, Middlesbrough and ${ }^{2}$ Centre for Oral Health Research, \\ School of Dental Sciences, Newcastle University, UK
}

Fluoride (F) has an important nutritional and public health impact due to its beneficial role in the mineralization of bones and teeth ${ }^{(1)}$ and with optimal usage it can reduce dental caries by up to $50 \%$. However, recent studies in industrialised and developing countries have shown an increase in the prevalence of dental fluorosis (tooth mottling) in both water-fluoridated and non water-fluoridated communities ${ }^{(2)}$ which appears to be due to chronic excessive ingestion of F, primarily from toothpastes. However, in view of the narrow gap between optimal and excessive $\mathrm{F}$ intake, considerable interest has also focused on studies involving measurement of dietary $\mathrm{F}$ intake, mainly using either 3-day food diary (3-d FD) or 2-day duplicate plate collection (2-d DP) methods. The aim of this study was to assess the agreement between 3-d FD and 2-d DP methods for daily dietary F intake of children.

Dietary data for 61 healthy children aged 4-6 years were collected using 3-d FD and 2-d DP methods with a one-week gap between each collection (randomised order). Duplicate diets were analysed for F by an acid-diffusion method ${ }^{(3)}$. Paired t-test and Bland-Altman limits of agreement were used to compare estimated dietary F intake by the two methods at group and individual levels, respectively. Due to a substantial relationship between differences and mean with the raw data (proportional bias), analysis was performed on log-transformed data providing ratio limits of agreement. However, the log-transformation did not completely eliminate the proportional bias, as seen in the plot.

\begin{tabular}{|c|c|c|c|c|c|c|c|}
\hline & \multicolumn{2}{|c|}{$\begin{array}{l}\text { Dietary F intake estimate } \\
\text { by } 3-\mathrm{d} \text { FD method }(\mathrm{mg} / \mathrm{d})\end{array}$} & \multicolumn{2}{|c|}{$\begin{array}{l}\text { Dietary F intake estimate } \\
\text { by } 2-\mathrm{d} \text { FD method }(\mathrm{mg} / \mathrm{d})\end{array}$} & \multicolumn{2}{|c|}{$\begin{array}{l}\text { Between-method differences } \\
\text { in dietary } \mathrm{F} \text { intake }(\mathrm{mg} / \mathrm{d})\end{array}$} & \multirow[b]{2}{*}{$P$ value } \\
\hline & Mean & $\mathrm{SD}$ & Mean & $\mathrm{SD}$ & Mean & $95 \% \mathrm{CI}$ & \\
\hline All drinks & 0.266 & 0.218 & 0.357 & 0.221 & -0.091 & $-0.140,-0.043$ & $<0.001$ \\
\hline All foods & 0.267 & 0.183 & 0.225 & 0.101 & +0.041 & $-0.001,+0.084$ & 0.06 \\
\hline Total & 0.533 & 0.319 & 0.583 & 0.263 & -0.050 & $-0.109,+0.009$ & 0.10 \\
\hline
\end{tabular}
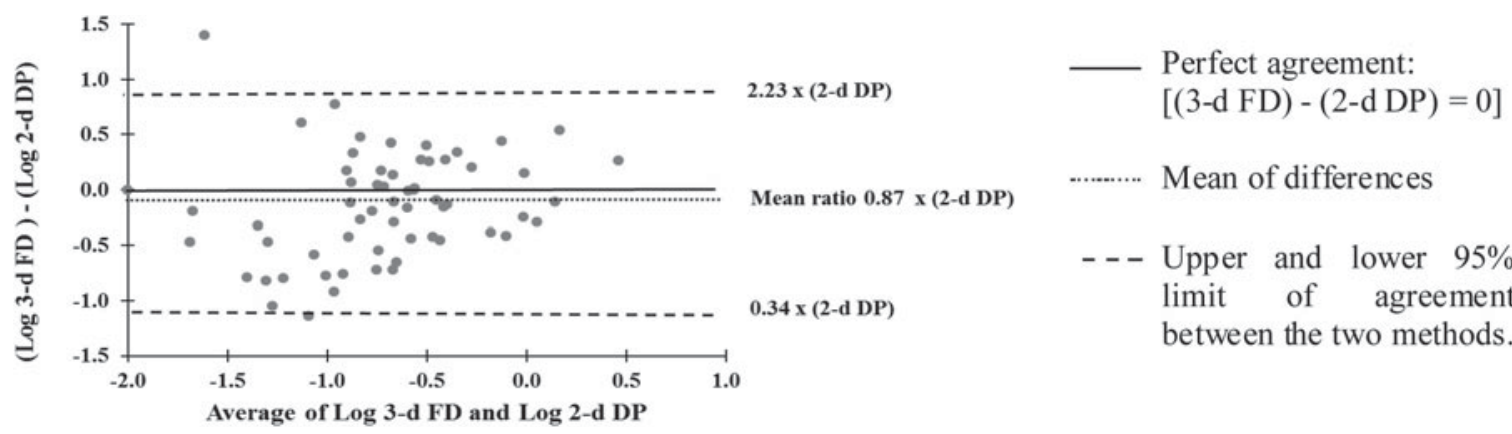

\begin{abstract}
The non-substantial difference in the mean total dietary F intake estimated by the 3-d FD vs. 2-d DP methods, at group level, suggests that either method can be used when estimating the mean total daily dietary F intake of a population. However, at the individual level, the wide limits of agreement for estimated total dietary F intake between the two dietary assessment methods indicated that these methods cannot be used interchangeably. In conclusion, based on the aim of the investigation, when determining the percentage of children with optimal, sub-optimal or excess $\mathrm{F}$ intake for implementing, evaluating or monitoring any systemic fluoridation, one of these two methods should be selected for use throughout the study.
\end{abstract}

Supported by grants from University of Teesside Research Doctoral Scholarships and The Borrow Foundation.

1. Palmer C \& Wolfre SH (2005) J Am Diet Assoc 105, 1620-1628.

2. Pendrys DG \& Stamm JW (1990) J Dent Res 69, 529-38.

3. Martínez-Mier EA, Cury JA, Heilman JR et al. (2011) Caries Res 45, 3-12. 